\title{
Shipping, Engineering and Machinery Exhibition
}

$\mathrm{O}^{\mathrm{N}}$ September 7 the Earl of Athlone opened the Shipping, Engineering and Machinery Exhibition at Olympia, London. Speaking optimistically of the trade outlook, he pointed to shipbuilding as an indication of the trend towards trade improvement. The Exhibition, in bringing together engineers from all parts of the world, will provide an impetus towards recovery. The improvement in the shipbuilding industry on the Clyde and the Tyne has been accompanied by a great increase in the tonnage of motorvessels and a feature of importance is the development of high-speed cargo vessels. At a luncheon later on, Lord Stonehaven said the exhibition is a tribute to the technical skill, ingenuity, courage and perseverance of those engaged in industry, while Prof. H. S. Hele-Shaw directed attention to the research exhibits and the display of nautical instruments.

During the time the Exhibition is open it will be visited officially by some sixty engineering, technical and scientific societies, and whether the individual members are interested in the commercial production, designing, or operating side of shipping and engineering, there is much that will interest them. The exhibits cover a very wide range and though it is primarily a shipping exhibition and centres around the machinery and equipment of ships of all kinds, it is equally an exhibition of mechanical engineering. With boiler and engine plants, air-compressing and refrigerating plants, are shown welding apparatus, filters, machine tools, drawing materials, lubricants, lighting plants, motors, and a great wealth of scientific instruments. As examples of workmanship the exhibits as a whole are of a very high standard, while one noticeable feature is that in design, finish and general appearance they satisfy the eye in the same manner as works of art.

On no fewer than twenty-four stands are to be seen various types of internal combustion engines and it is said that such a display has not previously been gathered together anywhere in the world. The exhibits include many types of Diesel engines with compressed air injection and oil engines with airless injection in which the fuel is injected direct from the fuel pump. The engines have anything from 1 to 8 cylinders, their power ranging up to 800 brake horse power, the fuel consumption in some cases being about $0.38 \mathrm{lb}$. of oil per horse power per hour. Amongst the oldest makers of Diesel engines in Great Britain is the firm of Messrs. Mirrlees, Bickerton and Day, Ltd., which has a stand, while other oil engine exhibitors include Messrs. Davey, Paxman and Co., Messrs. Allen of Bedford, and Messrs. Belliss and Morcom of Birmingham. This last firm was the pioneer some forty years ago in the development of the modern system of forced lubrication for engines, one of the greatest boons ever conferred on engineersin-charge.

Oil engines are extensively used aboard ship for driving auxiliaries, and for propulsion. They can be made reversible, or they can drive the propeller through reversing gear, or they can be used for oilelectric propulsion. On the stand of Messrs. Crossley Brothers, Ltd., is an 8-cylinder 600 b.h.p. engine similar to that used for operating the fast oil-electric ferry between Hong-Kong and Kowloon. Some of the firms exhibiting oil engines have examples also of steam turbines, turbo-generators and turbo-pumps, while turbine machinery development is illustrated by the exhibits of the companies founded by the late Sir Charles Parsons.

A notable steam exhibit is that of Messrs. Babcock and Wilcox, who show a section of an oil-fired watertube boiler as supplied to H.M.S. Guardian. Attention must also be directed to the Diesel shunting locomotive of Messrs. Sir W. G. Armstrong, Whitworth and Co (Engineers) Ltd., which runs to and fro on a track to demonstrate the ease with which it can be manipulated.

Of the extended use of instruments such as meters, gauges, indicators, recorders and controllers for the temperature, pressure, volume and flow of liquids and gases, the visitor will find ample evidence on the stands of such firms as Messrs. Elliott Bros. (London), Ltd., Foster Instrument Company, Negretti and Zambra, George Kent, Ltd., and others. They cover an amazingly wide field and are fully representative of the instruments found in every ship, every factory, every engineering works and all powerhouses. More intimately connected with shipping are the displays of radio apparatus by the International Marine Radio Co., Ltd., the Marine Electrical Equipment Co., Ltd., and the Marconi International Marine Communication Co., Ltd. Wireless is a necessity for all ships both large and small, and through the work of the Safety of Life at Sea Convention all passenger ships of 5,000 gross tons must now carry a wireless direction finder, while all compulsorily fitted ships which do not keep a watch throughout the twenty-four hours of the day have to be provided with an auto-alarm device by which the ship can receive a distress call from another ship at any time. The most recent installations of wireless telegraphy in passenger ships include a $2 \mathrm{kw}$. transmitter and are capable of communication on long, medium and short wave-lengths.

We have already briefly referred to the Industrial Research Exhibit arranged by the Department of Scientific and Industrial Research (see NATURE of September 9, p. 379). This is intended to show how research carried out by the Department itself and by various associated research bodies are assisting the shipping and engineering industries, and should enable visitors to obtain a closer knowledge of what is being done. An account of the exhibits is contained in a separate section of the catalogue, a copy of which should, if possible, be obtained beforehand. The price is $1 s$. Four research associations have collabor. ated with the Department of Scientific and Industrial Research. The exhibits range from ship model testing and research on pulverised fuel to the manufacture of iron and steel, the latest developments in the metallurgy of cast iron and the interesting work done by the British Non-Ferrous Metals Research Association.

The exhibition has been arranged with the active support of the British Engineers' Association, the Society of Motor Manufacturers and Traders, Ltd. and the British Marine Oil Engineer Manufacturers' Association, all of which are to be complimented on the varied, extensive and representative character of the collection of machinery and instruments which has been brought together. 